\title{
EGGSHELL ULTRASTRUCTURE OF NAKED NECK, FRIZZLE AND NORMALLY FEATHERED GENOTYPE CHICKENS
}

\author{
M.H. Mahrous
}

Department of Poultry Production, Faculty of Agriculture, University of Ain Shams, Cairo, Egypt

\section{SUMMARY}

An experiment was conducted to evaluate mechanical and ultrastructural properties of eggshell in naked neck (Nanaff), frizzled (nanaFf), naked neck-frizzled (NanaFf) and normally feathered (nanaff) genotypes. To assess eggshell quality, a total of 200 eggs (50 each genotype) were randomly collected at 35 weeks of age. The eggs produced from birds carrying Na gene in a single manner or interact with $F$ gene had owned better thickness and breaking strength of eggshell compared to other produced from nanaff sibs. The presence of Na gene in a single state or combined with $F$ gene significantly increased relative palisade thickness compared to nana genotype. Opposite trend was noticed for relative mammillary thickness. Type B bodies, which are rounded and located among mammillary caps, were more frequent in eggshell of nanaff genotype resulting in poor eggshell quality. However, Nanaff and NanaFf genotypes had good rounded caps and early fusion as compared to nanaff ones. In conclusion, the birds carrying Na gene in a single state or combined with $F$ gene had genetically not only better mechanical eggshell properties but also good ultrastructural formation of eggshell compared to normally feathered genotype.

Keywords: eggshell, ultrastructure, naked neck gene 